\title{
Exposure and Aversion to Human Transmissible Diseases Predict Conservative Ideological and Partisan Preferences
}

\author{
Authors: Brian A. O’Shea ${ }^{1,2 * \dagger}$, Joseph A. Vitriol ${ }^{1,3} \uparrow$, Christopher M. Federico ${ }^{4}$, Jacob \\ Appleby $^{5}$, Allison L. Williams ${ }^{6}$.
}

\begin{abstract}
Affiliations:
${ }^{1}$ Department of Psychology, Harvard University.

${ }^{2}$ Department of Psychology, University of Amsterdam

${ }^{3}$ Department of Political Science, Stony Brook University

${ }^{4}$ Departments of Political Science and Psychology, University of Minnesota.

${ }^{5}$ Department of Psychology, Hamline University.

${ }^{6}$ Beech Acres Parenting Center
\end{abstract}

*Correspondence concerning this article should be addressed to Brian O'Shea, Department of Psychology, Harvard University, 33 Kirkland St., Cambridge, MA 02138. E-mail: boshea@fas.harvard.edu.

$\uparrow$ These authors contributed equally to this work. A coin flip was used to determine the corresponding author.

Key Words: Infectious Diseases; Germ Aversion; Ideology; COVID-19; Non-zoonotic; Infectability. 


\begin{abstract}
The objective prevalence of and subjective vulnerability to infectious diseases are associated with greater in-group preference, conformity, and traditionalism. However, evidence directly testing the link between infectious diseases and political ideology and partisanship is lacking. Across four studies, including a large sample representative of the U.S. population $(\mathrm{N}>$ 12,000), we demonstrate that higher environmental levels of human transmissible diseases and avoidance of germs from human carriers predict conservative ideological and partisan preferences. During the COVID-19 pandemic $(\mathrm{N}=848)$, we replicated this germ aversion finding and determined that these conservative preferences were primarily driven by avoidance of germs from out-groups (foreigners) rather than in-groups (locals). Moreover, socially conservative individuals expressed lower concerns of being susceptible to contracting infectious diseases during the pandemic and worried less about COVID-19. These effects were robust to individual-level and state-level controls. We discuss these findings in light of theory on parasite stress and the behavioral immune system, and with regard to the political implications of the COVID-19 pandemic.
\end{abstract}


Infectious diseases were a major threat to the survival of human populations throughout history (Jones et al., 2008). Indeed, some scholars have estimated that they have accounted for more loss of human life than all wars, non-infectious diseases, and natural disasters combined (Inhorn \& Brown, 1990). In contrast to other threats to human welfare (e.g., intergroup violence), disease-causing parasites are largely imperceptible, and the origin and means of transmission were largely unknown prior to relatively recent scientific advancements (Murray \& Schaller, 2016). Consequently, traits, behaviors, cultural practices, and belief systems that facilitate the detection and avoidance of infectious diseases would have had evolutionary benefits for humans living in ancestral environments, leading to their retention through natural selection (Murray \& Schaller, 2016; Schaller, Park, \& Faulkner, 2003; Thornhill \& Fincher, 2014).

Parasite Stress Theory (PST) posits that objective regional differences in levels of infectious disease can predict cross-cultural variation in a range of traits, values, and beliefs (Thornhill \& Fincher, 2014). For example, environmental infectious disease prevalence is associated with preferences for in-group members and avoidance or exclusionary attitudes towards out-groups (Brown, Fincher, \& Walasek, 2016; Fincher \& Thornhill, 2008, 2012; O'Shea, Watson, Brown, \& Fincher, 2020), collectivistic (vs. individualistic) social structures (Fincher, Thornhill, Murray, \& Schaller, 2008; Morand \& Walther, 2018; Murray, Trudeau, \& Schaller, 2011), conventional social norms (van Leeuwen et al., 2012) and stronger adherence to traditionalism or authoritarianism (Thornhill, Fincher, \& Aran, 2009; Tybur et al., 2016; Zmigrod, Ebert, Götz, \& Rentfrow, 2020). Importantly, past research has relied on the RightWing Authoritarianism Scale (Tybur et al., 2016) or authoritarian childrearing values and U.S. state laws (Zmigrod et al., 2020) to estimate regional-level conservatism. Here we substantially enhance the specificity of the relationship between infectious diseases and political 
conservatism, by measuring participants' political leanings (i.e., Conservative vs. Liberal) and partisan preferences (i.e., Republican vs. Democrat) in the U.S. context.

Moreover, the effect of parasite stress on social attitudes and behavior should be constrained to human transmittable (non-zoonotic) pathogens. In contrast, zoonotic disease variants can only transfer from non-human animals to humans and, therefore, have minimal impact on human behavior (Thornhill, Fincher, Murray, \& Schaller, 2010). Yet this distinction between zoonotic and non-zoonotic parasites is rarely examined in the literature (Thornhill, Fincher, Murray, \& Schaller, 2010; for recent exceptions, see Mullett, Brown, Fincher, Kosinski, \& Stillwell, 2019; Zmigrod et al., 2020) and, to our knowledge, has not been investigated in relation to political ideology or partisanship in the U.S.

Whereas PST concerns the role of regional-level variation in infectious disease, the behavioral immune system examines individual-level hypersensitive detection and avoidance responses to cues that may signal a risk of infection (Murray \& Schaller, 2016; Schaller \& Park, 2011). For example, people negatively evaluate and avoid individuals with physical characteristics indicating illness or who are associated with disease (Kurzban \& Leary, 2001), and view with more suspicion members of unfamiliar out-groups who may be more likely to carry pathogens for which one lacks immunity (Faulkner, Schaller, Park, \& Duncan, 2004; Navarrete \& Fessler, 2006; Petersen, 2017). Importantly, hyper-vigilance towards potential human carriers of infectious disease has been observed in relation to both situational cues of infectious diseases (Murray \& Schaller, 2016; O’Shea et al., 2020), and individual differences in perceived vulnerability to disease (PVD; Aarøe, Petersen, \& Arceneaux, 2017; Duncan, Schaller, \& Park, 2009; Murray \& Schaller, 2016).

Individual differences in the perception of disease threats have also been implicated in a broad range of norms and practices that help protect the in-group and defend the cultural status quo. For example, social conformity increases when disease threat is made salient 
(Mortensen, Becker, Ackerman, Neuberg, \& Kenrick, 2010; Wu \& Chang, 2012), especially among individuals chronically high in PVD (Murray \& Schaller, 2012; Terrizzi Jr., Shook, \& McDaniel, 2013). However, in our view, these tendencies are more likely to relate to germ aversion rather than infectability concerns. To clarify, germ aversion is empirically associated with beliefs in a dangerous world, a need for order, and a desire to dominate out-groups, whereas infectability concerns are not (Duncan et al., 2009; O’Shea et al., 2020). Infectability concerns involve perceptions of one's immunological functioning and general susceptibility to infectious diseases, but it is not oriented towards mitigating pathogen transmission. In contrast, germ aversion measures avoidant behaviors towards potential carriers of disease, towards which strong motivational control processes can be exerted. Importantly, no research has directly examined whether the two PVD dimensions (i.e., infectability concerns and germ aversion) are differentially associated with political ideology and partisanship, despite its relevance to many of these aforementioned outcomes. Here, we predict that germ aversion will be more strongly implicated in the behavioral immune system than infectability concerns and will therefore, more strongly relate to conservative political ideology and partisanship.

\section{Infectious Disease, Pre-Political Orientations, Ideology and Partisanship}

The ensemble of tendencies activated by environmental levels of infectious disease and individual-level germ aversion may have implications for more abstract political predispositions, such as ideological self-placement, ideological affect, and identification with and affect towards political parties with different ideological reputations. Current work on the motivational foundations of political ideology and partisanship offers two especially important bases for these predictions.

First, many of the immediate behavioral immune system goals activated by infectious disease align very closely with the pre-political orientations and moral goals associated with political conservatism in U.S. and other Western contexts (e.g., Jost, Federico, \& Napier, 
2009). For example, the group-centrism elicited by the behavioral immune system shares a natural resonance with the emphasis on in-group loyalty associated with conservatism (Graham, Haidt, \& Nosek, 2009; Jost et al., 2009; van Leeuwen et al., 2012). Moreover, the emphasis on conformity and adherence to established norms produced by the behavioral immune system mirrors the premium conservatism places on social cohesion and the preservation of traditional lifeways and structures (Federico, Fisher, \& Deason, 2011; Tybur et al., 2016). We refer to these constructs as pre-political because while they may reflect beliefs about desirable patterns of social relations and have implications for civic life, they nonetheless lack direct linkages to beliefs about government, elected officials, public affairs, or policy prescriptions (Feldman, 1988). In the same way that political psychologists recognize that personality traits are distinct from political preferences even though it can shape political ideology (Vitriol, Larsen, \& Ludeke, 2019), we too view the implications of disease threat for psychological motivations, orientations, and values to be distinct from its implications for partisanship and ideology.

Second, beyond serving these value-based goals, current perspectives on political preferences argue that conservatism (like all ideological positions) serves deeper psychological needs. In particular, Jost, Glaser, Kruglanski, and Sulloway (2003) suggest that political conservatism is motivated by a general need to reduce threat and uncertainty. According to this view, conservatism serves these needs by resisting changes to the status quo that produce instability, disorder, and unforeseen harms (Johnston, Lavine, \& Federico, 2017; Jost et al., 2003; Jost, Stern, Rule, \& Sterling, 2017; Wu \& Chang, 2012).

Prior research has not directly investigated the relationship between environmental prevalence of infectious diseases or PVD and political partisanship and ideology. To be clear, existing work has examined the relationship between parasite stress or the behavioral immune system and a range of psychological factors or social orientations and values that may underpin 
or otherwise be associated with conservative political preferences (Aarøe et al., 2017; Terrizzi Jr. et al., 2013; Thornhill et al., 2009; Tybur et al., 2016). But none of these perspectives has directly linked the behavioral immune system to ideology or partisanship (for a recent exception see Aarøe, Petersen, \& Arceneaux, 2020, who used a measure of germ aversion to predict political preferences, but did not compare it to infectability concerns). More importantly, while these pre-political orientations and goals can lead to more conservative political preferences, these are nonetheless independent constructs from ideology and partisanship (Goren, Motta, \& Smith, 2020) that can have distinct impact on political judgment and behavior (Feldman, 2003; Goren, 2005). In general, underlying pre-political orientations do not always map directly onto political constructs, like ideology and partisanship, for all members of the general public (e.g., Federico et al., 2011; Federico \& Malka, 2018), and so the need to understand if or how disease threat directly shape political ideology and partisanship is pressing.

Furthermore, a related construct — disgust sensitivity—is associated with conservative social attitudes, identifications, and voting behavior (Aarøe et al., 2020; Inbar, Pizarro, Iyer, \& Haidt, 2012; Terrizzi Jr. et al., 2013; Tybur et al., 2016). While disgust sensitivity and PVD are related, they are distinct. For example, disgust can be elicited in response to moral and sexual cues but does not covary with environmental levels of parasite stress (Tybur et al., 2016; Tybur, Lieberman, \& Griskevicius, 2009). In our view, disgust is an inadequate proxy for PVD in that it fails to directly tap feelings of subjective infectability concerns or behavioral motivations to avoid germs from human carriers of disease (Duncan et al., 2009). Disgust sensitivity measures also focus on susceptibility to disgust as a general affective response, whereas PVD is conceptualized more specifically as a constellation of personal beliefs about infectability and the avoidance behaviors elicited when exposure to germs is heightened. As such, our main hypotheses remain unexamined. 


\section{Current Research}

In four studies, we test the hypothesis that environmental levels of non-zoonotic parasite stress and avoidance of germs from human carriers is related to conservative political ideology and partisanship. In Studies 1 and 2, we test our PST hypothesis by examining the relationship between various individual-level political ideology and partisanship and environmental levels of both non-zoonotic and zoonotic disease rates across states within the U.S. In Study 3, we test our behavioral immune system hypothesis, by examining political ideology and partisanship in relation to PVD. Study 4 conceptually replicates Study 3 using data gathered during the first peak phase of the COVID-19 outbreak in the U.S (April 2020). Empirical evidence consistent with our two hypotheses would provide strong support for the unique role of infectious disease and germ aversion in predicting political ideology and partisanship. In all studies, we expect our predicted effects to survive the inclusion of various controls that covary with political ideology and partisanship. All data, SPSS syntax, and R scripts for Study 1-4 are available at:

https://osf.io/mr7w4/?view_only=4ed50c6dceaa4383b1f124d544035844

\section{Study 1}

\section{Overview}

Using a non-represented U.S. sample, we provide the first test of our hypothesis consistent with PST: environmental levels of non-zoonotic (but not zoonotic) infectious disease rates predict conservative ideological self-placement and a stronger affective preference for the Republican Party over the Democratic Party.

\section{Participants and Procedure}

The sample consisted of volunteers $(N>1$ million) from the Project Implicit website (implicit.harvard.edu) who selected the President Task among 13 other potential tasks (e.g., 
Racism and Ageism tasks). Following the acceptance of informed consent, participants completed in random order the President Implicit Association Test (which involves categorization of good vs. bad trait words and images of the current U.S. president (at time of data collection) vs. past presidents), demographic questions, and various questions relating to a political party and president preferences. Data collection commenced in 2003. However, crucial demographic variables (see Table S1 for a full description of demographics) were not gathered until 2006. Therefore, the analyses were restricted between the years 2006-2019, and the data are available for public use (https://osf.io/f38ag/). Analyses were also restricted to participants within the 50 states of the U.S. The large final sample size $(N=385,972)$ ensures strong statistical power.

\section{Materials}

Ideological Self-Placement. Participants responded to the question "What is your political identity?" using a 7-point scale ranging from "Strongly Liberal" (1) to "Strongly Conservative.” (7). Throughout all studies, higher scores indicate a more conservative leaning or a greater preference for Republicans.

Affective Preference for Republicans over Democrats. The exact question posed was: "How warm or cold do you feel towards the following political party?" A zero (Extremely Cold) to ten (Extremely Warm) feeling thermometer was used to gauge each participant's attitude towards Republicans and Democrats separately. A relative political party feeling thermometer score was calculated by subtracting the Democratic feeling thermometer score from the Republican feeling thermometer score.

Non-zoonotic and zoonotic infectious diseases across the U.S. Fincher and Thornhill (2012) developed a general measure of infectious disease rates across the 50 U.S. states, which combined both non-zoonotic (58 varieties) and zoonotic (45 varieties) transmittable infectious diseases. This measure aggregates all infectious diseases reported by the U.S. Centers for 
Disease Control (CDC) for the years 1993-2007 for each state and divides the number of diseases by state population. Since infectious diseases are impacted by climate, we expect these figures to remain relatively stable over time. However, in 2014 the authors released separate metrics for non-zoonotic (which include diseases humans can contract from other humans as well as non-human animals (multi-host)) and zoonotic diseases (which humans can only contract from non-human animals) using the same data (Thornhill \& Fincher, 2014). We examine the independent effect of both the non-zoonotic and zoonotic measures in our analysis.

Robustness Checks. We used three different non-zoonotic disease metrics to test the robustness of the association between non-zoonotic diseases and political ideology. The first metric was from Shrira, Wisman, and Webster (2013), who developed estimates that included the eight most common non-zoonotic diseases (AIDS, Chlamydia, gonorrhea, syphilis, Hepatitis A, salmonellosis, shigellosis, and tuberculosis) across the 50 U.S. states between 1995-1999. These eight non-zoonotic diseases accounted for over $90 \%$ of all the infectious diseases reported by the CDC in the years analyzed. The second metric used estimates from Mullet et al., (2019) which uses the CDC's state-wise median infectious mortality rates for the years 1979-1998. The third metric was the same as the second, except it did not include rates of sexually transmitted disease. This modification to the index eliminates a potential confound with sexual life-history strategy, which has also been theorized to relate to political preferences (Figueredo et al., 2006; Weeden \& Kurzban, 2014).

Control variables. Five individual-level control variables were used. These variables included age, gender $(0=$ female and $1=$ male $)$, race $(0=$ non-white and $1=$ white $)$, education (ranging from $1=$ elementary school to $10=$ advanced degrees such as a Ph.D.), and religious belief $(1=$ not at all religious to $4=$ strongly religious $)$. The state-level controls included median income (logged), state inequality, percentage urban population, and percentage unemployed. Median income, inequality, and percentage unemployed used the American 
Community (ACS) Survey 5-year estimates (2008-2012), while 2010 ACS estimates were only available for percentage urban population.

Analysis. We used multilevel modeling with maximum likelihood estimation to analyze the data. We used linear mixed modeling and grouped participants by U.S. state. The model included a random intercept term at the U.S. state-level. We conducted two separate analyses, and the dependent variables for each analysis were ideological self-placement and affective preference for Republicans over Democrats. We added all the independent variables included in the model as fixed effects. Here and for Studies 2 - 4, we used z-scores for all predictors to allow for comparisons of the relative magnitude differences between the independent variable's fixed-effect estimates.

\section{Results}

Consistent with the PST, residents in U.S. states with a greater exposure to human transmittable (non-zoonotic) infectious diseases reported significantly higher levels of conservative ideological self-placement $(b=.042, t=3.76, p<.001$, see Figure 1A) and a stronger affective preference for the Republican Party over the Democratic Party $(b=.037, t=$ $3.33, p<.01$, see Figure 1B). Zoonotic diseases were unrelated to both these outcomes $(t \mathrm{~s}<$ $0.44, p s>.66)$. Crucially, these effects were obtained even with controls from five individuallevel (age, gender, race, education, religious belief) and four state-level (medium household income, inequality, \% unemployed, \% urban population) factors. See Table 1 for the full model. Emphasizing the robustness of the above findings, comparable results were shown using the three different metrics to estimate infectious disease rates (see Supplemental Materials; Table S2 summarizes the effects of the 8 most common non-zoonotic infectious diseases; Table S3 summarizes the effects of mortality due to infectious diseases with STDs included, and Table S4 with STDs excluded). 

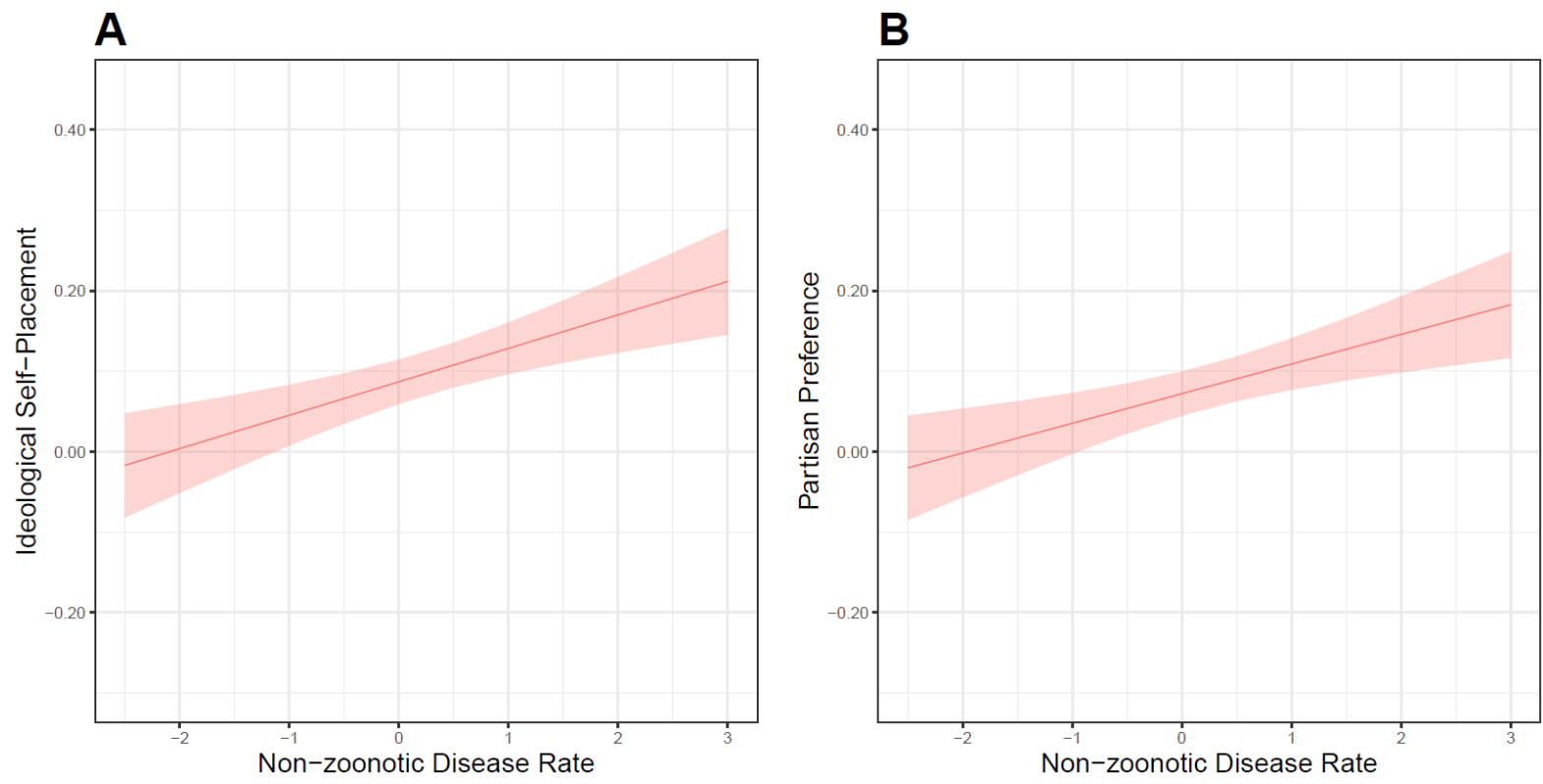

Fig. 1: Participants from U.S. states with higher infectious disease rates are (A) more conservative than liberal and (B) express stronger preferences for Republicans over Democrats. Study 1 plots showing the full multilevel models of Project Implicit data with all the control variables included. 
Table 1. Summary of Multilevel Analysis from Study 1 (Non-zoonotic Diseases)

\begin{tabular}{|c|c|c|c|c|c|c|}
\hline \multirow[b]{2}{*}{ Predictor } & \multicolumn{3}{|c|}{$\begin{array}{l}\text { Ideological Self-Placement } \\
\qquad(N=385,972)\end{array}$} & \multicolumn{3}{|c|}{$\begin{array}{l}\text { Affective Preference for } \\
\text { Republicans over Democrats } \\
\qquad(N=372,593)\end{array}$} \\
\hline & $b(95 \% C I)$ & $S E b$ & $t$ & $b(95 \% C I)$ & $S E b$ & $t$ \\
\hline Intercept & $0.08(0.05,0.10)$ & 0.01 & $5.52 * * *$ & $0.07(0.04,0.09)$ & 0.01 & $4.74 * * *$ \\
\hline Age & $0.01(0.01,0.01)$ & 0.00 & $5.03 * * *$ & $-0.04(-0.04,-0.04)$ & 0.00 & $-22.71 * * *$ \\
\hline Gender & $0.20(0.19,0.20)$ & 0.00 & $134.74 * * *$ & $0.20(0.19,0.20)$ & 0.00 & $128.28 * * *$ \\
\hline Race & $0.09(0.09,0.09)$ & 0.00 & $58.61 * * *$ & $0.17(0.17,0.17)$ & 0.00 & $107.48 * * *$ \\
\hline Education & $-0.15(-0.15,-0.14)$ & 0.00 & $-82.36 * * *$ & $-0.14(-0.14,-0.13)$ & 0.00 & $-71.00 * * *$ \\
\hline Religion & $0.85(0.85,0.86)$ & 0.00 & $262.49 * * *$ & $0.72(0.71,0.72)$ & 0.00 & $207.92 * * *$ \\
\hline Median Income & $-0.04(-0.06,-0.02)$ & 0.01 & $-3.83^{* * * *}$ & $-0.04(-0.06,-0.02)$ & 0.01 & $-3.58^{* * *}$ \\
\hline State Inequality & $-0.03(-0.06,0.00)$ & 0.01 & $-2.01 *$ & $-0.03(-0.06,0.00)$ & 0.01 & $-2.14 *$ \\
\hline$\%$ Unemployed & $-0.01(-0.03,0.02)$ & 0.01 & -0.62 & $-0.01(-0.04,0.01)$ & 0.01 & -0.94 \\
\hline$\%$ Urban & $-0.01(-0.03,0.02)$ & 0.01 & -0.52 & $-0.01(-0.03,0.01)$ & 0.01 & -0.84 \\
\hline Zoonotic & $0.01(-0.04,0.05)$ & 0.02 & 0.44 & $0.01(-0.04,0.05)$ & 0.02 & 0.28 \\
\hline Non-zoonotic & $0.04(0.02,0.06)$ & 0.01 & $3.76 * * *$ & $0.04(0.01,0.06)$ & 0.01 & $3.33 * *$ \\
\hline
\end{tabular}

Note: For the dependent variables, higher values indicate a conservative self-placement and a Republican preference. For the independent variables, higher values on each variable indicate older, male, white, more education, stronger religious belief, higher income, more inequality, higher unemployment, more urban populations, more zoonotic diseases, more non-zoonotic diseases. Individual-level controls are in italics. $\dagger p<.10, * p<.05, * * p<.01, * * * p<.001$. 


\section{Study 2}

\section{Overview}

Study 2 replicates Study 1 by using a sample representative of the U.S. population and includes two more dependent variables (i.e., ideological preference and political party selfplacement).

\section{Participants \& Procedure}

The American National Election Studies (ANES) cumulative time series data file was used, which is a pool of nationally-representative cross-sectional studies from multiple election years and includes a total sample of 59,944 respondents recruited between the years 1948 and 2016 (as described in more detail at https://electionstudies.org/data-center/anes-time-seriescumulative-data-file/). Questions that had been assessed in three or more ANES Time Series studies during this time period are included in this datafile and have been recoded, when necessary, to increase comparability across studies. We also restricted analyses to ANES data collected by between the years 1990 and 2016, since those years were in closest proximity to the state-level measures of pathogen load. Similar results were shown if participants from all the years were included. 10 states (AK, DE, HI, ME, MT, ND, RI, SD, VT, WY) had less than 50 respondents. Similar results to those reported here were found if these 10 states were removed from the analysis. The final sample size used $(N>12,000)$ again ensures strong statistical power (see Table S5 for demographics).

\section{Materials}

Ideological Self-Placement. Each participant responded to a variant of the following question: "We hear a lot of talk these days about liberals and conservatives. Here is a 7-point scale on which the political views that people might hold and are arranged from extremely 
liberal to extremely conservative. Where would you place yourself on this scale, or haven't you thought much about this?"

Affective Preference for Conservatives over Liberals. Participants completed the 0 - 100 feeling thermometer items for conservatives and liberals, comparable to Study 1. A relative score was created by subtracting participants' feeling thermometer ratings of liberals from their feeling-thermometer ratings of conservatives.

Partisan identification. Each participant completed a variation of the following question: "Generally speaking, do you usually think of yourself as a Republican, a Democrat, an Independent, or what? Do you think of yourself as closer to the Republican or Democratic party? $(1=$ Strong Democrat, $2=$ Weak Democrat, $3=$ Independent, lean Democrat, $4=$ pure Independent, 5 = Independent, lean Republican, $6=$ Weak Republican, $7=$ Strong Republican).

Affective Preference for Republicans over Democrats. The same feeling thermometer questions as above were posed to each participant, with 'Democrat' and 'Republican' as the target groups. A relative score was created by subtracting participants' feeling thermometer ratings of Democrats from their feeling-thermometer ratings of Republicans.

Non-zoonotic and zoonotic infectious diseases across the U.S. These variables were operationalized the same way as in Study 1.

Robustness Checks. These variables were operationalized the same way as in Study 1.

Additional control variables. Seven individual-level control variables were used. These variables included age, gender $(0=$ female and $1=$ male $)$, race $(0=$ non-white and $1=$ white), education $(1=$ grade school or less, $2=$ high school or less, $3=$ some college, $4=$ college or advanced degree), the importance of religion in the participant's life $(1=$ not important to $4=$ a great deal $)$, income $(1=$ lowest percentile to $5=$ highest percentile $)$, political 
knowledge $(1=$ very low to $4=$ very high $)$. Political Knowledge was indexed by the number of correct responses to 3 items that assessed knowledge of the job or office held by the named (1) Speaker of the House, (2) Vice President (3) Chief Justice of the Supreme Court. All items were scored on a binary $(0=$ incorrect or no answer, $1=$ correct $)$ basis. The state-level controls were the same as study 1 .

Analysis. The analysis was carried out in the same fashion as in Study 1, but now four dependent variables were used (ideological self-placement, affective preference for conservatives over liberals, partisan identification, and affective preference for Republicans over Democrats). 


\section{Results}

\section{Study 2}

Again in line with PST, we find that residents in states with greater exposure to nonzoonotic diseases displayed significantly stronger conservative ideological self-placement $(b$ $=.041, t=2.67, p<.001$, see Figure 2A) and greater Republican party identification $(b=.046$, $t=2.32, p=.024$, see Figure 2B), even with all the covariates from Study 1 included in the model, as well as individual-level income and political knowledge covariates. Moreover, these residents also expressed more positive relative feelings towards conservatives $(b=.044, t=$ 2.78, $p<.01$, see Figure 2C) and Republicans $(b=.039, t=2.16, p=.036$, see Figure 2D), even after all the covariates were included. Zoonotic diseases were unrelated to these outcomes ( $t$ s $<1.48, p s>.148)$. See Table 2 for the full model. Similar to Study 1, comparable results to the non-zoonotic metrics reported here were observed when the three robustness checks were used (see Table S6, S7 \& S8) ${ }^{1}$.

\footnotetext{
1 A reviewer indicated that the relationship between conservatism and higher infectious diseases may be due to conservative health policies. To rule out this possibility and to further emphasize the unique contribution of non-zoonotic diseases, we included state-level government healthcare expenditure as a covariate to all the models in Study 1 and 2. Lower health care expenditure was consistently related to conservative political preferences, but crucially, the relationship between infectious disease and conservative political preferences remained substantially unchanged. See Supplemental Materials for details.
} 

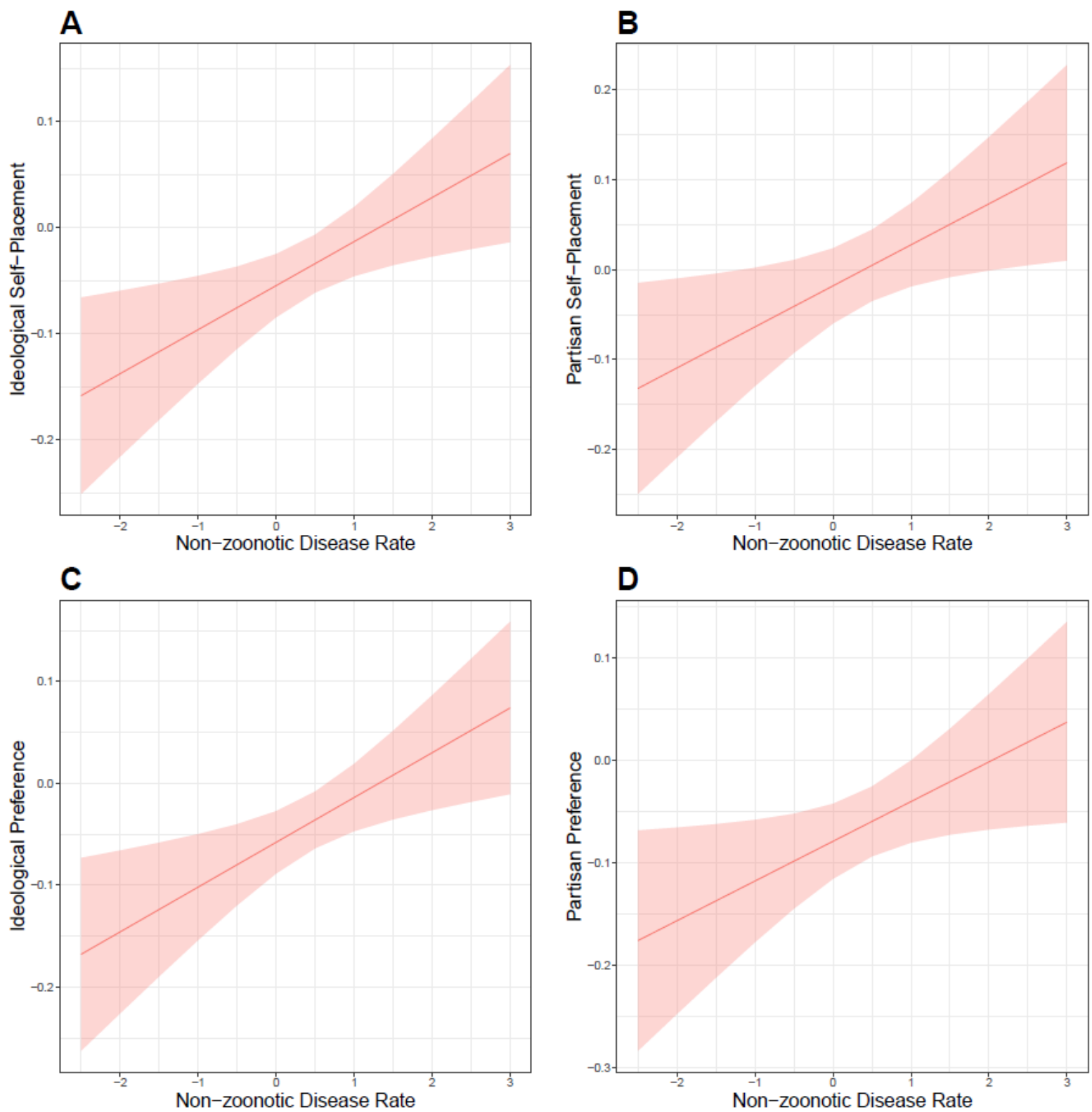

Fig. 2: Respondents from U.S. states with higher infectious disease rates are more likely to identify as (A) conservative, and (B) Republican, as well as express an affective preference for (C) conservatism and (D) Republicanism. Study 2 plots showing the full multilevel models of American National Election Studies data with all the control variables included. 
Table 2. Summary of Multilevel Analysis from Study 2 (Non-zoonotic Diseases)

\begin{tabular}{|c|c|c|c|c|c|c|c|c|c|c|c|c|}
\hline \multirow[b]{2}{*}{ Predictor } & \multicolumn{3}{|c|}{$\begin{array}{l}\text { Ideological Self-Placement } \\
\qquad(N=12,111)\end{array}$} & \multicolumn{3}{|c|}{$\begin{array}{l}\text { Partisan Identification } \\
\qquad(N=14,623)\end{array}$} & \multicolumn{3}{|c|}{$\begin{array}{c}\text { Affective Preference for } \\
\text { Conservatives over Liberals } \\
\qquad(N=14,078)\end{array}$} & \multicolumn{3}{|c|}{$\begin{array}{l}\text { Affective Preference for Republicans } \\
\text { over Democrats } \\
(N=14,420)\end{array}$} \\
\hline & $b(95 \% C I)$ & $S E b$ & $t$ & $b(95 \% C I)$ & $S E b$ & $t$ & $b(95 \% C I)$ & $S E b$ & $t$ & $b(95 \% C I)$ & $S E b$ & $t$ \\
\hline Intercept & $0.03(-0.01,0.06)$ & 0.02 & 1.62 & $0.07(0.03,0.11)$ & 0.02 & $3.27 * *$ & $0.04(0.01,0.08)$ & 0.02 & $2.71 * *$ & $0.03(-0.01,0.07)$ & 0.02 & 1.63 \\
\hline Age & $0.07(0.05,0.06)$ & 0.01 & $7.28 * * *$ & $-0.05(-0.06,-0.03)$ & 0.01 & $-5.56 * * *$ & $0.04(0.02,0.06)$ & 0.01 & $4.47 * * *$ & $-0.03(-004 .,-0.01)$ & 0.01 & $-2.81 * *$ \\
\hline Gender & $0.11(0.10,0.13)$ & 0.01 & $12.67 * * *$ & $0.10(0.08,0.11)$ & 0.01 & $12.50 * * *$ & $0.11(0.09,0.13)$ & 0.01 & $12.39 * * *$ & $0.10(0.09,0.12)$ & 0.01 & $12.05 * *$ \\
\hline Race & $0.15(0.14,0.17)$ & 0.01 & $17.71 * * *$ & $0.30(0.28,0.31)$ & 0.01 & $39.77 * * *$ & $0.20(0.18,0.22)$ & 0.01 & $23.12 * * *$ & $0.33(0.31,0.34)$ & 0.01 & $39.67 * *$ \\
\hline Education & $-0.09(-0.11,-0.07)$ & 0.01 & $-7.80 * * *$ & $0.02(0.004,0.04)$ & 0.01 & $2.33^{*}$ & $0.09(-0.11,-0.06)$ & 0.01 & $-7.64 * * *$ & $-0.01(-0.04,0.01)$ & 0.01 & -1.30 \\
\hline Religion & $0.30(0.28,0.31)$ & 0.01 & $32.52 * * *$ & $0.16(0.14,0.17)$ & 0.01 & $19.39 * * *$ & $0.29(0.27,0.31)$ & 0.01 & $31.44 * * *$ & $0.19(0.17,0.20)$ & 0.01 & $21.05 * *$ \\
\hline Income & $0.07(0.05,0.09)$ & 0.01 & $7.17 * * *$ & $0.10(0.08,0.12)$ & 0.01 & $11.20 * * *$ & $0.08(0.06,0.10)$ & 0.01 & $7.56^{* * *}$ & $0.11(0.09,0.13)$ & 0.01 & $11.15^{* *}$ \\
\hline Political Knowledge & $-0.01(-0.03,0.01)$ & 0.01 & -1.26 & $-0.01(-0.23,0.01)$ & 0.01 & -0.64 & $-0.01(-0.03,0.01)$ & 0.01 & -1.24 & $-0.02(-0.03,0.004)$ & 0.01 & -1.60 \\
\hline Median Income & $-0.04(-0.07,-0.01)$ & 0.01 & $-2.93 * *$ & $-0.01(-0.05,0.03)$ & 0.02 & -0.53 & $0.04(-0.07,-0.01)$ & 0.01 & $-2.56^{*}$ & $-0.03(-0.07,0.002)$ & 0.02 & $-1.88 \dagger$ \\
\hline State Inequality & $-0.03(-0.07,0.004)$ & 0.02 & $-1.82 \dagger$ & $-0.03(-0.08,0.01)$ & 0.02 & -1.40 & $-0.03(-0.07,0.01)$ & 0.02 & -1.48 & $-0.02(-0.06,0.03)$ & 0.02 & -0.86 \\
\hline$\%$ Urban Population & $-0.001(-0.03,0.03)$ & 0.01 & -0.08 & $-0.01(-0.05,0.03)$ & 0.02 & -0.59 & $0.01(-0.02,0.04)$ & 0.01 & 0.50 & $0.01(-0.03,0.04)$ & 0.02 & 0.40 \\
\hline$\%$ Unemployed & $-0.004(-0.04,0.03)$ & 0.02 & -0.27 & $-0.02(-0.07,0.02)$ & 0.02 & -1.16 & $0001(-0.03,0.03)$ & 0.02 & -0.01 & $-0.02(-0.05,0.02)$ & 0.02 & -0.87 \\
\hline Zoonotic & $0.03(-0.03,-0.08)$ & 0.03 & 0.93 & $-0.01(-0.08,0.06)$ & 0.04 & -0.23 & $0.04(-0.02,0.10)$ & 0.03 & 1.48 & $0.02(-0.05,0.08)$ & 0.03 & 0.51 \\
\hline Non-zoonotic & $0.04(0.01,0.07)$ & 0.02 & $2.67 *$ & $0.05(0.01,0.08)$ & 0.02 & $2.32 *$ & $0.04(0.01,0.01)$ & 0.02 & $2.78 * *$ & $0.04(0.003,0.07)$ & 0.02 & $2.16 *$ \\
\hline
\end{tabular}

Note: For the dependent variables, higher values indicate a conservative and Republican self-placement, as well as an affective preference for conservatives and Republicans. For the independent variables, higher values on each variable indicate older, male, white, more education, stronger religious belief, higher income, greater political knowledge, higher state income, more inequality, higher unemployment, more urban populations, more zoonotic diseases, and more non-zoonotic diseases. Individual-level controls are in italics.

$\dagger p<.10, * p<.05, * * p<.01, * * * p<.001$. 


\section{Study 3}

\section{Overview}

Study 3 took the form of a three-wave study to test our behavioral immune system hypothesis by examining whether germ aversion (but not infectability concerns) predict political conservatism.

\section{Participants and Procedure}

The University of Minnesota granted Institutional Review Board (IRB) approval because the participants were undergraduate students enrolled in psychology courses there $(N$ $=261 ; 205$ females and 56 males; mean age $=19.97, S D=2.96$; see Table $S 9$ ). We aimed for at least 250 participants; recruitment was stopped once we reached the number of sign-ups that would permit this goal to be reached. Twenty-seven participants were excluded for not being U.S. citizens, leaving us with a final sample of 234. Participants volunteered for the study in exchange for extra credit in one or more of their psychology courses. Upon registration, all participants were emailed a link to an online survey for the first wave of the study (Time 1; T1) and instructed to complete it immediately after checking a box to indicate informed consent. Two days after completing the T1 survey, participants were recontacted via an email prompt with a link to a second online survey (T2). All participants completed both surveys between October 10 and November 5, 2012. Approximately two months later (T3), participants were re-contacted a third time to complete a survey that measured their voting behavior in the 2012 U.S. Presidential Election. Table S9 reports the demographic characteristics of participants in Study 3.

We rely upon data from T1 and T2 in the analysis for Study 3. In the main text, we report models using T1 independent variables and T2 dependent variables. However, some of our dependent measures were administered at both time points. Results for analyses using the 
T1 dependent variables are reported in the Supplemental Materials, which indicate the same results as those reported in the main text.

\section{Materials}

Below, we describe our measures. Measures not included in this analysis (but administered for research questions not addressed in the current study) are described in the Supplemental Materials. Table S10 provides the means, standard deviations, scale alphas, and intercorrelations between variables included in this analysis.

Perceived Vulnerability to Disease (PVD). This was assessed at T1 using a 15-item measure developed and validated by Duncan, Schaller, and Park (2009). The PVD scale assesses individual differences in persistent concerns about germ contraction and susceptibility to infectious disease and is composed of two factors. The first factor is composed of 7 items, and measures beliefs about one's immune system and personal susceptibility to infectious disease (Infectability Concern). The second factor is composed of 8 items and assesses aversion to situations, interactions, and people that pose a relatively high risk of pathogen transmission (Germ Aversion). Participants responded to each item on a 1 (strongly disagree) to 7 (strongly agree) scale. Responses were then averaged separately for each factor.

Ideological Self-Placement. This was assessed at T1 and T2 using a single item asking respondents to place themselves on a 7-point scale ranging from "Very Liberal" (1) to "Very Conservative.” (7).

Affective Preference for Conservatives over Liberals. Global evaluations of liberals and conservatives were assessed at T2 using 101-point feeling thermometers ranging from 0 ("positive") to 100 ("negative"). Responses were reversed, so higher scores indicated more positive evaluations, and evaluations of liberals were subtracted from those of conservatives. 
Partisan Identification. This was assessed at T1 and T2 using a single item asking respondents to place themselves on a 7-point scale ranging from "Strong Democrat" to "Strong Republican.”

Affective Preference for Republicans over Democrats. Global evaluations of Democrats and Republicans were assessed at T2 using 101-point feeling thermometers ranging from 0 ("positive") to 100 ("negative"). Responses were reversed, so higher scores indicated more positive evaluations, and evaluations of Democrats were subtracted from those of Republicans.

Political Knowledge. This was indexed by the number of correct responses to the following items: (1) "What job or political office does Joseph Biden currently hold?" (2) "What job or political office does John Roberts currently hold?” (3) “What job or political office does David Cameron currently hold?" (4) "What job or political office does John Boehner currently hold?" (5) "In what country does Kim Jong-un serve in a leadership role?" (6) "Which political party currently has the most members in the Senate in Washington?" (7) "Which political party currently has the most members in the House of Representatives in Washington?" (8) "How long is the term of office for a U.S. Senator?" (9) "Whose responsibility is it to nominate judges to the Federal Courts - the President, the Congress, or the Supreme Court?" All items were scored on a binary $(0=$ incorrect or no answer, $1=$ correct $)$ basis.

Needs for Certainty and Security: Need for Cognitive Closure. As a control for needs for certainty and security (e.g., Federico \& Malka, 2018), we included a consistent psychological predictor of ideological self-placement in previous studies: the need for cognitive closure, which reflects a desire for certainty and a preference for firm, unchanging answers to questions (Jost et al., 2003). The need for cognitive closure was assessed at T1 using a shortened, 14-item version of Kruglanski, Pierro, Mannetti, and De Grada, (2006) original 
scale. Participants rated their agreement with each item on a 6-point scale ranging from 1 (strongly disagree) to 6 (strongly agree).

Demographics. We also included three demographic controls, measured at T1. One was a standard demographic measure: age (in years). Moreover, given research showing greater conservatism among men (e.g., Sidanius \& Pratto, 2001), we considered gender $(1=$ female, $0=$ male), and in light of work connecting higher income to conservatism (e.g., Gelman, Park, Shor, \& Cortina, 2010), we also assessed family income (11-point scale, in increments of $\$ 10,000)$.

Analysis. We regressed each of our four dependent variables-ideological selfplacement, affective preference for conservatives over liberals, partisan identification, and affective preference for Republicans over Democrats—on age, gender, income, need for cognitive closure, political knowledge and both perceived infectability and germ aversion. The statistical effect of concern about contracting disease from human carriers (i.e., germ aversion) is therefore estimated net of the effect of demographics, more general concern about infectability, and pre-existing individual differences in a major "competing" psychological predictor of political ideology (i.e., needs for certainty and security, as indexed by the need for closure).

\section{Results}

As hypothesized, germ aversion (but not infectability concern) was a significant predictor of conservative ideological self-placement $(b=0.16$, CI 95\% $(0.02,0.30), p=.022)$, affective preference for conservatives (vs. liberals; $b=0.17$, CI 95\% $(0.03,0.31), p=.019)$, Republican identification $(b=0.14$, CI 95\% (-0.002, 0.27), $p=.054)$, and affective preference for Republicans (vs. Democrats; $b=0.20$, CI 95\% $(0.06,0.33), p=.005)$. To ensure robustness, these effects where shown when controlling for other factors related to political preferences. Table S10 provides the means, standard deviations, scale alphas, and intercorrelations between 
variables included in this analysis. The regression estimates from this analysis are summarized in Table 3 (and Table S11). 
Table 3. Perceived Vulnerability to Disease, Political Preferences (Study 3)

\begin{tabular}{|c|c|c|c|c|c|c|c|c|c|c|c|c|}
\hline \multirow[b]{2}{*}{ Predictor } & \multicolumn{3}{|c|}{ Ideological Self-Placement } & \multicolumn{3}{|c|}{ Partisan Identification } & \multicolumn{3}{|c|}{$\begin{array}{c}\text { Affective Preference for } \\
\text { Republicans over Democrats }\end{array}$} & \multicolumn{3}{|c|}{$\begin{array}{c}\text { Affective Preference for } \\
\text { Conservatives over Liberals }\end{array}$} \\
\hline & $b(95 \% C I)$ & $S E b$ & $t$ & $b(95 \% C I)$ & $S E b$ & $t$ & $b(95 \% C I)$ & $S E b$ & $t$ & $b(95 \% C I)$ & $S E b$ & $t$ \\
\hline Intercept & $0.39(0.10,0.68)$ & 0.15 & $2.69 * *$ & $0.35(0.06,0.63)$ & 0.14 & $2.39 *$ & $0.42(0.13,0.71)$ & 0.15 & $2.87 * *$ & $0.32(0.04,0.61)$ & 0.14 & $2.26^{*}$ \\
\hline Age & $-0.10(-0.23,0.04)$ & 0.07 & $-1.42 \dagger$ & $-0.13(-0.26,0.01)$ & 0.07 & $-1.86 \dagger$ & $-0.06(-0.20,0.07)$ & 0.07 & -0.90 & $-0.14(-0.27,-0.003)$ & 0.07 & $-2.02 *$ \\
\hline Gender & $-0.49(-0.82,-0.17)$ & 0.16 & $-2.98 * *$ & $0.44(-0.77,-0.12)$ & 0.16 & $-2.70 * *$ & $0.53(-0.85,-0.20)$ & 0.17 & $-3.18 * *$ & $-0.41(-0.73,-0.09)$ & 0.16 & $-2.53^{*}$ \\
\hline Family income & $0.08(-0.05,0.22)$ & 0.07 & 1.26 & $0.12(-0.02,0.25)$ & 0.07 & 1.75 & $0.10(-0.03,0.23)$ & 0.07 & 1.48 & $0.13(0.00,0.27)$ & 0.07 & $2.02 *$ \\
\hline Pol. Knowledge & $-0.07(-0.21,0.06)$ & 0.07 & -1.11 & $-0.11(-0.24,0.02)$ & 0.07 & -1.70 & $-0.07(-0.21,0.06)$ & 0.07 & -1.12 & $-0.10(-0.23,0.03)$ & 0.07 & -1.56 \\
\hline Need for closure & $0.11(-0.02,0.24)$ & 0.07 & $1.69 \dagger$ & $0.08(-0.05,0.21)$ & 0.07 & 1.17 & $0.09(-0.04,0.22)$ & 0.07 & 1.32 & $0.05(-0.08,0.18)$ & 0.07 & 0.81 \\
\hline Infectability Concern & $-0.00(-0.15,0.14)$ & 0.07 & -0.01 & $0.02(-0.13,0.16)$ & 0.07 & 0.22 & $0.04(-0.11,0.18)$ & 0.07 & 0.53 & $-0.03(-0.17,0.12)$ & 0.07 & -0.38 \\
\hline Germ Aversion & $0.16(0.10,0.68)$ & 0.07 & $2.31 *$ & $0.14(-0.002,0.27)$ & 0.07 & $1.94 \dagger$ & $0.17(0.03,0.31)$ & 0.07 & $2.36^{*}$ & $0.20(.06,0.33)$ & 0.07 & $2.81 * *$ \\
\hline$F(\mathrm{dF})$ & \multicolumn{3}{|l|}{$4.25(7,220)^{* *}$} & \multicolumn{3}{|c|}{$4.25(7,220)^{* *}$} & \multicolumn{3}{|c|}{$4.09(7,218)^{* *}$} & \multicolumn{3}{|c|}{$4.95(7,220)^{* *}$} \\
\hline Adjusted $R^{2}$ & \multicolumn{3}{|l|}{0.09} & \multicolumn{3}{|l|}{0.09} & \multicolumn{3}{|c|}{0.09} & \multicolumn{3}{|l|}{0.11} \\
\hline$N$ & \multicolumn{3}{|l|}{228} & \multicolumn{3}{|l|}{228} & \multicolumn{3}{|c|}{226} & \multicolumn{3}{|l|}{228} \\
\hline
\end{tabular}

Note. Entries are ordinary least-squares standardized regression coefficients and standard errors. All variables are standardized. Germ Aversion is a measure of perceived concern of human carriers of disease. For the dependent variables, higher values indicate a conservative and Republican self-placement and increased preference for Republicans/conservatives over Democrats/liberals. For the independent variables, higher values on each variable indicate older, male, white, more education, higher income, more political knowledge, higher need for closure, more infectability concern, and greater germ aversion.

$\dagger p<.10, * p \leq .05, * * p<.01, * * * p<.001$. 


\section{Study 4}

\section{Overview}

Using a large convenience sample, Study 4 conceptually replicates the findings of Study 3 during COVID-19 pandemic with respect to ideological self-placement, but also separately examines domain-specific ideological self-placement in the economic (e.g., taxation, government spending) and social (e.g., abortion, gun control, gay rights) realms. We further examine the extent to which the effects of germ aversion on political preferences are constrained to concerns about out-group (but not in-group) members.

\section{Participants and Procedure}

Harvard University granted IRB approval for this study. 2,572 Project Implicit volunteers began our study, but due to dropout, and a requirement that only U.S. residents could be included in the analysis, 1,182 participants remained. Each regression analysis had between 842 and 860 participants due to missing data from the variables included. Data collection for this study began on the $28^{\text {th }}$ of March 2020, and we arbitrarily chose to download the data and analyze it on the $21^{\text {st }}$ of April 2020. This date was chosen for three reasons. First, we had finished analyzing, and writing-up the data and results of Study 1-3. Second, the U.S. had passed the predicted peak (14-15 $5^{\text {th }}$ of April, 2020) of the first wave of the COVID-19 outbreak. Third, it is important to test whether our hypothesized results for germ aversion and infectability hold up amid (1) objective pandemic conditions and (2) related political messaging that might conceivably reduce PVD specifically among conservatives (Motta, Stecula, \& Farhart, 2020). After selecting a button to indicate agreement with the informed consent, participants completed in random order, demographic questions, various questionnaires, including measures of implicit and explicit attitudes that evaluated the extent to which Americans, Chinese, Britons, and Italians are associated with infection (vs. health). Only the variables that are relevant to our research question were analyzed. 


\section{Materials}

Ideological Self-Placement. Participants responded to the question, "What is your political identity?" using a 7-point scale ranging from "Strongly Liberal" (1) to "Strongly Conservative." (7).

Social Issue Self-Placement. Participants responded to the question, "Please indicate your political identity on social issues (e.g., abortion, gun control, gay rights)," using a 7-point scale ranging from "Strongly Liberal" (1) to "Strongly Conservative." (7).

Economic Issue Self-Placement. Participants responded to the question, "Please indicate your political identity on economic issues (e.g., taxation, government spending)," using a 7-point scale ranging from "Strongly Liberal" (1) to "Strongly Conservative." (7).

COVID-19 concern. Participants responded to the item, "How worried are you personally about Coronavirus?" using a 4-point scale ranging from (1) "Not worried at all" to (4) "Very Worried."

Perceived Vulnerability to Disease (PVD). This scale was administered in the same way as described in Study 3.

In-group Germ Avoidance. Four items were adapted from the PVD germ aversion subscale. These items focused on avoiding germs from participants' local region and included: (1) I try to avoid using public toilets in my local region because of the risk that I may catch something from the previous user. (2) I am comfortable eating street food in my local region. (3) I often use hand sanitizer in my local region. (4) I am comfortable sharing a water bottle with a stranger from my local region. The same 1-7 Likert scale as the PVD scale was used here.

Out-group Germ Avoidance. This adapted scale used the same items as above, except “developing countries" replaced "local region”. See Table S16 for additional analyses showing 
that the associations between germ aversion and political, economic, and social ideology, are fully explained by out-group, rather than in-group, germ avoidance.

Control variables. The same individual-level demographic variables as Study 1 were used as controls. As in Study 3, here we control for age, gender, and general concerns about infectability. However, measures of political knowledge and need for closure were not available. Instead, we include the following as additional controls: education, race, religion, and most importantly, a single item measuring how worried participants were about COVID19.

Analysis. We regressed each of our three dependent variables-ideological selfplacement, economic issue self-placement, and social issue self-placement —on age, gender, race, education, religious belief, COVID-19 concern, and both perceived infectability and germ aversion. The statistical effect of concern about contracting disease from human carriers (i.e., germ aversion) is therefore estimated after controlling for the effect of demographics, concerns about COVID-19, and more general infectability concerns.

\section{Results}

The results of these analyses are summarized in Table 4. Again, the results indicate that germ aversion (but not infectability concern), was a significant predictor of conservative ideological self-placement $(b=0.08$, CI 95\% $(0.02,0.14), p=.01)$. Similarly, higher germ aversion predicts conservative social attitudes $(b=0.09$, CI 95\% $(0.04,0.15), p=.002)$, and we also extend this finding to conservative economic attitudes $(b=0.07, \mathrm{CI} 95 \%(0.00,0.13)$, $p=.03)$.

However, we also find that those with lower infectability concerns are more likely to express socially conservative (vs. liberal; $b=-0.10$, CI 95\% $(-0.15,-0.04), p=.002)$ positions. Of note, throughout the three analyses, participants who expressed less worry about COVID19 held more conservative positions. We speculate that individuals with conservative 
preferences are taking cues about the severity of COVID-19 from like-minded political elites and media outlets (Motta et al., 2020). Finally, we adapted the germ aversion subscale to determine whether ideology was primarily related to the avoidance of germs from those in your local region (in-groups) or developing countries (out-groups). As shown in Table S16, germ aversion from out-groups (but not in-groups) consistently predicted ideology (political, economic, and social). 
Table 4. Perceived Vulnerability to Disease, Political, Social and Economic Identification (Study 4)

\begin{tabular}{|c|c|c|c|c|c|c|c|c|c|}
\hline \multirow[b]{2}{*}{ Predictor } & \multicolumn{3}{|c|}{ Ideological Self-Placement } & \multicolumn{3}{|c|}{ Economic Issue Self-Placement } & \multicolumn{3}{|c|}{ Social Issue Self-Placement } \\
\hline & $b(95 \% C I)$ & $S E b$ & $t$ & $b(95 \% C I)$ & $S E b$ & $t$ & $b(95 \% C I)$ & $S E b$ & $t$ \\
\hline Intercept & $0.00(-0.06,0.05)$ & 0.03 & -0.12 & $0.01(-0.05,0.07)$ & 0.03 & 0.37 & $-0.00(-0.06,0.05)$ & 0.03 & -.13 \\
\hline Age & $0.00(-0.08,0.08)$ & 0.04 & 0.02 & $-0.03(-0.11,0.05)$ & 0.04 & -0.76 & $0.06(-0.02,0.13)$ & 0.04 & 1.53 \\
\hline Gender & $0.16(0.10,0.22)$ & 0.03 & $5.40 * * *$ & $0.16(0.10,0.23)$ & 0.03 & $5.15^{* * *}$ & $0.18(0.12,0.24)$ & 0.03 & $6.19 * * *$ \\
\hline Race & $0.13(0.08,0.20)$ & 0.03 & $4.42 * * *$ & $0.18(0.11,0.24)$ & 0.03 & $5.52 * * *$ & $0.10(0.04,0.15)$ & 0.03 & $3.25 * * *$ \\
\hline Education & $-0.20(-0.28,-0.13)$ & 0.04 & $-5.23 * * *$ & $-0.16(-0.24,-0.08)$ & 0.04 & $-4.05 * * *$ & $-0.21(-0.28,-0.14)$ & 0.04 & $-5.72 * * *$ \\
\hline Religion & $0.36(0.30,0.41)$ & 0.03 & $11.86^{* * *}$ & $0.27(0.21,0.33)$ & 0.03 & $8.59 * * *$ & $0.43(0.38,0.49)$ & 0.03 & $15.07 * * *$ \\
\hline COVID-19 Concern & $-0.17(-0.24,-0.11)$ & 0.03 & $-5.56 * * *$ & $-0.16(-0.22,-0.09)$ & 0.03 & $-4.79 * * *$ & $-0.16(-0.22,-0.10)$ & 0.03 & $-5.24 * * *$ \\
\hline Infectability Concern & $-0.05(-0.11,0.01)$ & 0.03 & -1.52 & $-0.05(-0.12,0.01)$ & 0.03 & -1.60 & $-0.10(-0.15,-0.04)$ & 0.03 & $-3.15^{* *}$ \\
\hline Germ Aversion & $0.08(0.02,0.14)$ & 0.03 & $2.51 * *$ & $0.07(0.00,0.13)$ & 0.03 & $2.12 *$ & $0.09(0.04,0.15)$ & $\mathbf{0 . 0 3}$ & 3.16 ** \\
\hline$F(\mathrm{dF})$ & \multicolumn{3}{|c|}{$37.35(8,851)^{* * *}$} & \multicolumn{3}{|c|}{$25.77(8,839)^{* * *}$} & \multicolumn{3}{|c|}{$50.87(8,839) * * *$} \\
\hline Adjusted $R^{2}$ & \multicolumn{3}{|l|}{0.25} & \multicolumn{3}{|l|}{0.19} & \multicolumn{3}{|l|}{0.32} \\
\hline$N$ & \multicolumn{3}{|l|}{860} & \multicolumn{3}{|l|}{848} & \multicolumn{3}{|l|}{848} \\
\hline
\end{tabular}

Note. Entries are ordinary least-squares standardized regression coefficients and standard errors. All variables are standardized. Germ Aversion is a measure of perceived concern of human carriers of disease. For the dependent variables, higher values indicate a politically, economically, and socially conservative self-placement. For the independent variables, higher values on each variable indicate older, male, white, more education, stronger religious belief, greater COVID-19 concern, more infectability concern, and greater germ aversion.

$\dagger p<.10, * p<.05, * * p<.01, * * * p<.001$ 


\section{Discussion}

Across four studies, we substantially extend prior work on PST and the behavioral immune system by examining the relationship between political partisanship and ideology, and environmental levels of non-zoonotic diseases and avoidance of germs from human carriers. Study 1 found that individual-level ideological self-placement and affective preference for the Republican (vs. Democratic) Party were related to higher environmental levels of non-zoonotic (but not zoonotic) parasite stress in a large convenience sample, a set of findings we replicate in Study 2 using a sample representative of the American population. Extending these regionallevel findings to the individual-level, Study 3 found that germ aversion (but not general concerns about infectability) was associated with more conservative identifications and preferences. Study 4 also provided a conceptual replication amid the U.S. COVID-19 outbreak and extended the findings to conservative economic preferences. Moreover, individuals in Study 4 with socially conservative issue preferences also showed weaker infectability concerns. Perhaps this outcome was impacted by cues from conservative media downplaying the seriousness of the pandemic (Motta et al., 2020), which might lead some to overestimate their immune system functioning or under-estimate the health-risks posed by COVID-19. Importantly, in all cases, our results were robust to controls for relevant demographics, competing psychological determinants of political preferences, and (in Study 1 and 2) a wide range of state-level controls.

Together, our results clarify the link between parasite stress and political preferences by examining the relative effects of environmental levels of both zoonotic and non-zoonotic pathogens, and demonstrate its implications for specifically political ideology and partisanship, rather than simply using proxies for conservatism (e.g., traditionalism; Tybur et al., 2016) . Our findings also address a major gap in our understanding of the political implications of the behavioral immune system. Although perceived vulnerability to disease has been shown to 
predict conformity (Murray \& Schaller, 2012; Wu \& Chang, 2012), in-group preference (Fincher \& Thornhill, 2012), and exclusionary attitudes toward out-groups (O'Shea et al., 2020), the current studies uncover how germ aversion and infectability are distinctly related to conservative ideological and partisan preferences among U.S. participants. Moreover, we suspect that past researchers might have overlooked the importance of specifically the germ aversion dimension because the infectability concern dimension is unrelated (Study 3) or negatively related (Study 4) to conservative political preferences. To clarify, when both the germ aversion and the infectability concern dimensions of the PVD scale are combined to create a total PVD score, which is a more common approach (see Terrizzi et al., 2013), this total score was inconsistently related (Study 3; see Tables S12 \& S13) or unrelated (Study 4; see Table S17) to conservative political preferences.

In Study 4 (Supplemental Materials), we also show that germ aversion towards outgroups (foreigners) rather than in-groups (locals) relates more strongly to conservative political preferences. Recently, Tybur, Lieberman, Fan, Kupfer, and de Vries (2020) showed that participants take more disease contact risks with those who have higher interpersonal value (i.e., in-group members). Along these lines, during a pandemic like COVID-19, when movement restrictions are in place, one may be more likely to contract the disease from members of the in-group rather than out-groups, due to the higher likelihood of contact with members of the same social group. Since conservatives show a stronger preference for interaction with in-groups (Graham et al., 2009), it is possible that they may be motivated to downplay the threat of the virus (i.e., lower fear of COVID-19) if it primarily comes (imperceptibly) from interaction with valued in-group members. However, if a threat is primarily confined (perceptibly) to out-groups, especially foreigners, perhaps conservatives will instead exaggerate the threat (c.f. Crawford, 2017). Future research would benefit from unpacking these speculations. 
Given the relatively abstract nature of ideology and partisanship as identifications and the details of specific political issues (Federico \& Malka, 2018; Jost et al., 2009), our findings thus suggest that the effects of parasite stress and operation of the behavioral immune system may also have implications for outcomes less concrete and socially immediate than simple ingroup bias, out-group prejudice, or social conformity. Methodologically, our results provide a more precise look at the relationship between political preferences and the behavioral immune system than studies that rely solely on disgust sensitivity as an indicator of pathogen-avoidance motives, which have yielded weak (Aarøe et al., 2020) or inconsistent findings (Tybur et al., 2016). By relying on more direct indicators of (a) objective environmental exposure to parasites transmittable by human carriers (i.e., non-zoonotic pathogens), and (b) pathogen avoidance that accounts for both subjective perceptions of susceptibility to infection and germ avoidance motivations, our results explicate the connection between political preferences, parasite stress, and the behavioral immune system. We would expect similar finding to those reported above within other nations, as well as across nations, however further research in this regard is needed.

Despite the strength of our evidence, our studies are not without limitations. Above all, our correlational data cannot provide decisive evidence for a causal link between vulnerability to disease and political partisanship and ideology. Our datasets are all cross-sectional, and they do not experimentally manipulate vulnerability to non-zoonotic pathogens in a way that allows for causal identification. Nonetheless, evidence we present has a number of broader implications, for society in general, for the political implications of the COVID-19 pandemic, and for future research. Like other threat variables (e.g., Federico \& Malka, 2018; Johnston et al., 2017; Jost et al., 2017, p. 20), increased attention to public health concerns associated with infectious disease - both in communications from political elites and in media coverage of ongoing events- have the potential to produce a conservative shift in public opinion and 
ideological and partisan sympathies (e.g., Schaller, Hofer, \& Beall, 2017). However, caveats are warranted here.

First, most evidence on the link between disease threats and political preferences is correlational in nature (c.f., Karwowski et al., 2020), so we must take care in offering causal interpretations. Second, perceptions of disease concern may themselves become endogenous to and limited in their effects by partisan signals. As noted above, right-leaning elites and media sources have downplayed COVID-19, potentially dampening concern among conservatives and Republicans (Conway, Woodard, Zubrod, \& Chan, 2020; Motta et al., 2020); indeed, our Study 4 data confirmed this pattern. Consistent with this line of reasoning, Samore, Fessler, Sparks, and Holbrook (2020) find that social conservatism is correlated with increased COVID-19 precaution among Democrats but not Republicans.

Lastly, given the tendency for pathogen prevalence to produce strong reactions against cultural out-groups and those who deviate from dominant social norms (e.g., Thornhill \& Fincher, 2014; Tybur et al., 2016), we also expect these effects to be especially strong when disease threats are associated with "foreign" groups (e.g., West Africans in the case of Ebola or Chinese in the case of COVID-19) or "non-normative" groups (e.g., gay men in the case of HIV). Political elites that demonize or scapegoat groups may find a more receptive electorate. These questions await future research. 


\section{References}

Aarøe, L., Petersen, M. B., \& Arceneaux, K. (2017). The Behavioral Immune System Shapes Political Intuitions: Why and How Individual Differences in Disgust Sensitivity Underlie Opposition to Immigration. American Political Science Review, 111(2), 277-294. https://doi.org/10.1017/S0003055416000770

Aarøe, L., Petersen, M. B., \& Arceneaux, K. (2020). The Behavioral Immune System Shapes Partisan Preferences in Modern Democracies: Disgust Sensitivity Predicts Voting for Socially Conservative Parties. Political Psychology, 41(6), 1073-1091. https://doi.org/10.1111/pops.12665

Brown, G. D. A., Fincher, C. L., \& Walasek, L. (2016). Personality, parasites, political attitudes, and cooperation: A model of how infection prevalence influences openness and social group formation. Topics in Cognitive Science, 8(1), 98-117. https://doi.org/10.1111/tops.12175

Conway, L. G., Woodard, S. R., Zubrod, A., \& Chan, L. (2020). Why are Conservatives Less Concerned about the Coronavirus (COVID-19) than Liberals? Testing Experiential Versus Political Explanations [Preprint]. PsyArXiv. https://doi.org/10.31234/osf.io/fgb84

Crawford, J. T. (2017). Are Conservatives More Sensitive to Threat than Liberals? It Depends on How We Define Threat and Conservatism. Social Cognition, 35(4), 354373. https://doi.org/10.1521/soco.2017.35.4.354

Duncan, L. A., Schaller, M., \& Park, J. H. (2009). Perceived vulnerability to disease: Development and validation of a 15-item self-report instrument. Personality and Individual Differences, 47(6), 541-546. https://doi.org/10.1016/j.paid.2009.05.001 
Faulkner, J., Schaller, M., Park, J. H., \& Duncan, L. A. (2004). Evolved disease-avoidance mechanisms and contemporary xenophobic attitudes. Group Processes \& Intergroup Relations, 7(4), 333-353. https://doi.org/10.1177/1368430204046142

Federico, C. M., Fisher, E. L., \& Deason, G. (2011). Expertise and the Ideological Consequences of the Authoritarian Predisposition. Public Opinion Quarterly, 75(4), 686-708. https://doi.org/10.1093/poq/nfr026

Federico, C. M., \& Malka, A. (2018). The Contingent, Contextual Nature of the Relationship Between Needs for Security and Certainty and Political Preferences: Evidence and Implications. Political Psychology, 39(S1), 3-48. https://doi.org/10.1111/pops.12477

Feldman, S. (1988). Structure and Consistency in Public Opinion: The Role of Core Beliefs and Values. American Journal of Political Science, 32(2), 416-440. https://doi.org/10.2307/2111130

Feldman, S. (2003). Values, ideology, and the structure of political attitudes. In Oxford handbook of political psychology (pp. 477-508). New York, NY, US: Oxford University Press.

Figueredo, A. J., Vásquez, G., Brumbach, B. H., Schneider, S. M. R., Sefcek, J. A., Tal, I. R., ... Jacobs, W. J. (2006). Consilience and Life History Theory: From genes to brain to reproductive strategy. Developmental Review, 26(2), 243-275. https://doi.org/10.1016/j.dr.2006.02.002

Fincher, C. L., \& Thornhill, R. (2008). Assortative sociality, limited dispersal, infectious disease and the genesis of the global pattern of religion diversity. Proceedings of the Royal Society of London B: Biological Sciences, 275(1651), 2587-2594. https://doi.org/10.1098/rspb.2008.0688 
Fincher, C. L., \& Thornhill, R. (2012). Parasite-stress promotes in-group assortative sociality: The cases of strong family ties and heightened religiosity. Behavioral and Brain Sciences, 35(02), 61-79. https://doi.org/10.1017/S0140525X11000021

Fincher, C. L., Thornhill, R., Murray, D. R., \& Schaller, M. (2008). Pathogen prevalence predicts human cross-cultural variability in individualism/collectivism. Proceedings of the Royal Society of London B: Biological Sciences, 275(1640), 1279-1285. https://doi.org/10.1098/rspb.2008.0094

Gelman, A., Park, D., Shor, B., \& Cortina, J. (2010). Red State, Blue State, Rich State, Poor State: Why Americans Vote the Way They Do (Expanded Edition). Princeton University Press. JSTOR. https://doi.org/10.2307/j.ctt7sx24

Goren, P. (2005). Party Identification and Core Political Values. American Journal of Political Science, 49(4), 881-896. https://doi.org/10.1111/j.1540-5907.2005.00161.x

Goren, P., Motta, M., \& Smith, B. (2020). The Ideational Foundations of Symbolic Ideology. Political Psychology, 41(S1), 75-94. https://doi.org/10.1111/pops.12683

Graham, J., Haidt, J., \& Nosek, B. A. (2009). Liberals and conservatives rely on different sets of moral foundations. Journal of Personality and Social Psychology, 96(5), 10291046. https://doi.org/10.1037/a0015141

Inbar, Y., Pizarro, D., Iyer, R., \& Haidt, J. (2012). Disgust Sensitivity, Political Conservatism, and Voting. Social Psychological and Personality Science, 3(5), 537544. https://doi.org/10.1177/1948550611429024

Inhorn, M. C., \& Brown, P. J. (1990). The anthropology of infectious disease. Annual Review of Anthropology, 19, 89-117. https://doi.org/10.1146/annurev.an.19.100190.000513 Johnston, C. D., Lavine, H. G., \& Federico, C. M. (2017). Open versus Closed: Personality, Identity, and the Politics of Redistribution. Cambridge University Press. 
Jones, K. E., Patel, N. G., Levy, M. A., Storeygard, A., Balk, D., Gittleman, J. L., \& Daszak, P. (2008). Global trends in emerging infectious diseases. Nature, 451(7181), 990993. https://doi.org/10.1038/nature06536

Jost, J. T., Federico, C. M., \& Napier, J. L. (2009). Political Ideology: Its Structure, Functions, and Elective Affinities. Annual Review of Psychology, 60(1), 307-337. https://doi.org/10.1146/annurev.psych.60.110707.163600

Jost, J. T., Glaser, J., Kruglanski, A. W., \& Sulloway, F. J. (2003). Political conservatism as motivated social cognition. Psychological Bulletin, 129(3), 339-375. https://doi.org/10.1037/0033-2909.129.3.339

Jost, J. T., Stern, C., Rule, N. O., \& Sterling, J. (2017). The Politics of Fear: Is There an Ideological Asymmetry in Existential Motivation? Social Cognition, 35(4), 324-353. https://doi.org/10.1521/soco.2017.35.4.324

Karwowski, M., Kowal, M., Groyecka, A., Bialek, M., Lebuda, I., Sorokowska, A., \& Sorokowski, P. (2020). When in Danger, Turn Right: Covid-19 Threat Promotes Social Conservatism and Right-Wing Presidential Candidates [Preprint]. PsyArXiv. https://doi.org/10.31234/osf.io/pjfhs

Kruglanski, A. W., Pierro, A., Mannetti, L., \& De Grada, E. (2006). Groups as epistemic providers: Need for closure and the unfolding of group-centrism. Psychological Review, 113(1), 84-100. https://doi.org/10.1037/0033-295X.113.1.84

Kurzban, R., \& Leary, M. R. (2001). Evolutionary origins of stigmatization: The functions of social exclusion. Psychological Bulletin, 127(2), 187-208. https://doi.org/10.1037//0033-2909.127.2.187

Morand, S., \& Walther, B. A. (2018). Individualistic values are related to an increase in the outbreaks of infectious diseases and zoonotic diseases. Scientific Reports, 8(1), 3866. https://doi.org/10.1038/s41598-018-22014-4 
Mortensen, C. R., Becker, D. V., Ackerman, J. M., Neuberg, S. L., \& Kenrick, D. T. (2010). Infection breeds reticence: The effects of disease salience on self-perceptions of personality and behavioral avoidance tendencies. Psychological Science, 21(3), 440447. https://doi.org/10.1177/0956797610361706

Motta, M., Stecula, D., \& Farhart, C. (2020). How Right-Leaning Media Coverage of COVID-19 Facilitated the Spread of Misinformation in the Early Stages of the Pandemic in the U.S. Canadian Journal of Political Science. Revue Canadienne De Science Politique, 1-8. https://doi.org/10.1017/S0008423920000396

Mullett, T. L., Brown, G. D. A., Fincher, C. L., Kosinski, M., \& Stillwell, D. (2019). Individual-Level Analyses of the Impact of Parasite Stress on Personality: Reduced Openness Only for Older Individuals: Personality and Social Psychology Bulletin. https://doi.org/10.1177/0146167219843918

Murray, D. R., \& Schaller, M. (2012). Threat(s) and conformity deconstructed: Perceived threat of infectious disease and its implications for conformist attitudes and behavior. European Journal of Social Psychology, 42(2), 180-188. https://doi.org/10.1002/ejsp.863

Murray, D. R., \& Schaller, M. (2016). The behavioral immune system. In J. M. Olson \& M. P. Zanna, Advances in Experimental Social Psychology (Vol. 53, pp. 75-129). New York: Academic Press.

Murray, D. R., Trudeau, R., \& Schaller, M. (2011). On the Origins of Cultural Differences in Conformity: Four Tests of the Pathogen Prevalence Hypothesis. Personality and Social Psychology Bulletin, 37(3), 318-329. https://doi.org/10.1177/0146167210394451

Navarrete, C. D., \& Fessler, D. M. T. (2006). Disease avoidance and ethnocentrism: The effects of disease vulnerability and disgust sensitivity on intergroup attitudes. 
Evolution and Human Behavior, 27(4), 270-282.

https://doi.org/10.1016/j.evolhumbehav.2005.12.001

O’Shea, B. A., Watson, D. G., Brown, G. D. A., \& Fincher, C. L. (2020). Infectious Disease Prevalence, Not Race Exposure, Predicts Both Implicit and Explicit Racial Prejudice Across the United States. Social Psychological and Personality Science, 11(3), 345355. https://doi.org/10.1177/1948550619862319

Petersen, M. B. (2017). Healthy Out-Group Members Are Represented Psychologically as Infected In-Group Members. Psychological Science, 28(12), 1857-1863. https://doi.org/10.1177/0956797617728270

Samore, T., Fessler, D. M. T., Sparks, A. M., \& Holbrook, C. (2020). Of Pathogens and Party Lines: Social Conservatism Positively Associates with COVID-19 Precautions among U.S. Democrats but not Republicans. PsyArXiv. https://doi.org/10.31234/osf.io/9zsvb

Schaller, M., Hofer, M. K., \& Beall, A. T. (2017). Evidence That an Ebola Outbreak Influenced Voting Preferences, Even After Controlling (Mindfully) for Autocorrelation: Reply to Tiokhin and Hruschka (2017). Psychological Science, 28(9), 1361-1363. https://doi.org/10.1177/0956797617718183

Schaller, M., Park, J., \& Faulkner, J. (2003). Prehistoric dangers and contemporary prejudices. European Review of Social Psychology, 14(1), 105-137. https://doi.org/10.1080/10463280340000036

Schaller, M., \& Park, J. H. (2011). The Behavioral Immune System (and Why It Matters). Current Directions in Psychological Science, 20(2), 99-103. https://doi.org/10.1177/0963721411402596 
Shrira, I., Wisman, A., \& Webster, G. D. (2013). Guns, Germs, and Stealing: Exploring the Link between Infectious Disease and Crime. Evolutionary Psychology, 11(1), 147470491301100. https://doi.org/10.1177/147470491301100124

Sidanius, J., \& Pratto, F. (2001). Social Dominance: An Intergroup Theory of Social Hierarchy and Oppression. Cambridge University Press.

Terrizzi Jr., J. A., Shook, N. J., \& McDaniel, M. A. (2013). The behavioral immune system and social conservatism: A meta-analysis. Evolution and Human Behavior, 34(2), 99108. https://doi.org/10.1016/j.evolhumbehav.2012.10.003

Thornhill, R., \& Fincher, C. L. (2014). The Parasite-Stress Theory of values and sociality. Cham: Springer International Publishing.

Thornhill, R., Fincher, C. L., \& Aran, D. (2009). Parasites, democratization, and the liberalization of values across contemporary countries. Biological Reviews, 84(1), 113-131. https://doi.org/10.1111/j.1469-185X.2008.00062.X

Thornhill, R., Fincher, C. L., Murray, D. R., \& Schaller, M. (2010). Zoonotic and nonzoonotic diseases in relation to human personality and societal values: Support for the parasite-stress model. Evolutionary Psychology, 8(2), 151-169. https://doi.org/10.1177/147470491000800201

Tybur, J. M., Inbar, Y., Aarøe, L., Barclay, P., Barlow, F. K., De Barra, M., ... others. (2016). Parasite stress and pathogen avoidance relate to distinct dimensions of political ideology across 30 nations. Proceedings of the National Academy of Sciences, 201607398.

Tybur, J. M., Lieberman, D., Fan, L., Kupfer, T. R., \& de Vries, R. E. (2020). Behavioral Immune Trade-Offs: Interpersonal Value Relaxes Social Pathogen Avoidance. Psychological Science, 31(10), 1211-1221. https://doi.org/10.1177/0956797620960011 
Tybur, J. M., Lieberman, D., \& Griskevicius, V. (2009). Microbes, mating, and morality: Individual differences in three functional domains of disgust. Journal of Personality and Social Psychology, 97(1), 103-122. https://doi.org/10.1037/a0015474

van Leeuwen, F., Park, J. H., Koenig, B. L., \& Graham, J. (2012). Regional variation in pathogen prevalence predicts endorsement of group-focused moral concerns. Evolution and Human Behavior, 33(5), 429-437. https://doi.org/10.1016/j.evolhumbehav.2011.12.005

Vitriol, J. A., Larsen, E. G., \& Ludeke, S. G. (2019). The Generalizability of Personality Effects in Politics. European Journal of Personality, 33(6), 631-641. https://doi.org/10.1002/per.2222

Weeden, J., \& Kurzban, R. (2014). The Hidden Agenda of the Political Mind. Princeton University Press. JSTOR. https://doi.org/10.2307/j.ctt6wq15d

Wu, B.-P., \& Chang, L. (2012). The social impact of pathogen threat: How disease salience influences conformity. Personality and Individual Differences, 53(1), 50-54. https://doi.org/10.1016/j.paid.2012.02.023

Zmigrod, L., Ebert, T., Götz, F., \& Rentfrow, J. (2020). The Psychological and Sociopolitical Consequences of Infectious Diseases. PsyArXiv. https://doi.org/10.31234/osf.io/84qcm 